SHORT REPORT

\title{
Angiocentric immunoproliferative lesion and angiocentric lymphoma of lymph node in children. A report of two cases
}

\section{R Drut, R M Drut}

J Clin Pathol 2005;58:550-552. doi: 10.1136/icp.2004.022475

\begin{abstract}
Aim: To report two examples of an angiocentric immunoproliferative lesion (AIL) and angiocentric angiodestructive lymphoma (AL) presenting in lymph nodes in children. Most commonly involving extranodal sites, AIL/AL rarely presents in the spleen and lymph nodes.

Methods/Results: Case 1 presented as a cervical lymphadenopathy in a 3 year old girl being treated for pre-B cell acute lymphoblastic leukaemia. Histological and immunohistochemistry studies revealed an Epstein-Barr virus positive $(\mathrm{EBV}+)$, large $\mathrm{B}$ cell (CD20 and CD30+) AlL with large areas of necrosis, the whole resembling lymphomatoid granulomatosis. Case 2 presented as a large supraclavicular lymphadenopathy in a 13 year old boy. Histology and immunohistochemistry revealed an EBV-, large $T$ cell (CD45RO, CD56, and CD30+) AL, presenting the features of so called angiocentric T cell/natural killer cell lymphoma, nasal type.

Conclusions: The term AlL/AL refers to a heterogeneous group of conditions not unique to a particular type of lymphoid cell. These lesions are easily recognised by the histopathologist because of their extremely unusual angiocentric pattern. Although rare, AlL/AL may present as nodal lesions in children ab initio.
\end{abstract}

A ngiocentric immunoproliferative lesions (AIL) and angiocentric angiodestructive lymphomas (AL) encompass a heterogeneous group of conditions that have an unusual tendency to present and involve extranodal sites such as lung, skin, sinonasal areas, intestine, and brain. The main proliferative cells may be of the B cell, T cell, or T cell/ natural killer (NK) cell phenotype. Occasionally, this peculiar pattern develops in children. ${ }^{1-3}$ Rarely, AIL/AL presents as nodal disease. ${ }^{4}$ Nodal AL has been reported once in a young patient, ${ }^{5}$ but in the largest series all patients were at least 27 years old. ${ }^{4}$

Our present report describes two examples of nodal AIL/AL in children.

\section{CASE 1}

A 2 year, 10 month old girl presented in May 2001 with weakness, fever, and hepatosplenomegaly. The peripheral white blood cell count was $100 \times 10^{9} /$ litre, with $89 \%$ of blasts. Flow cytometry revealed 99\% CD45+ cells, 97\% CD19+ cells, 86\% CD20+ cells, 96\% CD22+ cells, 92\% CD34+ cells, 86\% CD10+ cells, 92\% HLA-DR+ cells, and $81 \%$ terminal deoxynucleotidyl transferase positive cells. The case was interpreted as a pre-B cell acute lymphoblastic leukaemia (ALL), stage III, FAB Ll. The patient received steroids and cranial radiotherapy ( $12 \mathrm{~Gy}$ ). After treatment, the patient's white blood cell counts returned to normal. On November 2002, the girl presented with an enlarged, $4 \times 4.5 \mathrm{~cm}$ lymphadenopathy on the left side of the neck. Human immunodeficiency virus and Epstein-Barr virus (EBV) serology were negative. After the diagnosis rendered with the lymph node biopsy the patient continued her treatment for the leukaemia. Currently (August 2004), she is alive and well.

The material was received as a consultation case. Histological sections showed a lymph node almost completely effaced by irregularly shaped foci of necrosis related to angiocentric and angiodestructive polymorphic cellular infiltrates, which occasionally obliterated the vessels. The foci of necrosis were limited by histiocytes and fibroblasts, focally arranged in a pattern suggesting palisade granulomas, although clearcut granulomas were not present. Among the vascular related cellular infiltrates large lymphoid cells with clear cytoplasm and a prominent lobulated or rounded nucleus with a prominent nucleolus were easily noticed. Some were arranged in concentric rings around the vessels. These cells also extended to the interfollicular areas in the more preserved zones of the lymph node. Immunohistochemistry revealed that the large cell component was CD20+ (fig 1) and CD30+. These lymphomatous cells were associated with a large number of $\mathrm{CD} 45 \mathrm{RO}+\mathrm{T}$ cell polymorphic lymphocytes, which were prominent in the angiocentric lesions (fig 2). In situ hybridisation for EBV encoded RNA was positive in the large lymphomatous cells (fig 3). Both the histological picture and the immunohistochemical findings were reminiscent of that of lymphomatoid granulomatosis.

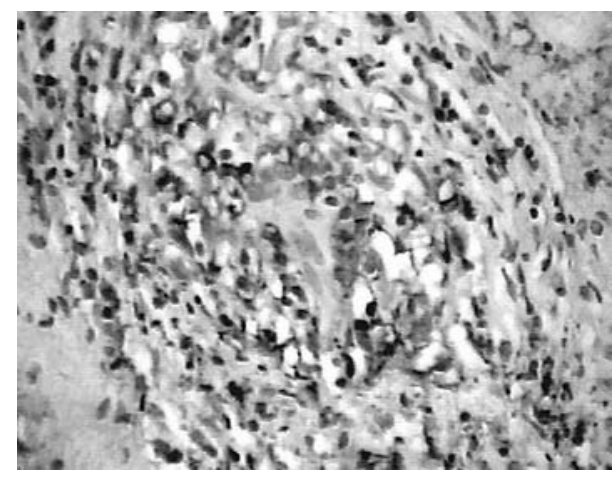

Figure 1 Polymorphic angiocentric proliferation with CD20+ large cells arranged around the vessel. The lower left hand corner depicts an area of necrosis. Case 1.

Abbreviations: AlL, angiocentric immunoproliferative lesion; $\mathrm{AL}$ angiocentric lymphoma; ALL, acute lymphoblastic leukaemia; EBV, Epstein-Barr virus; NK, natural killer 


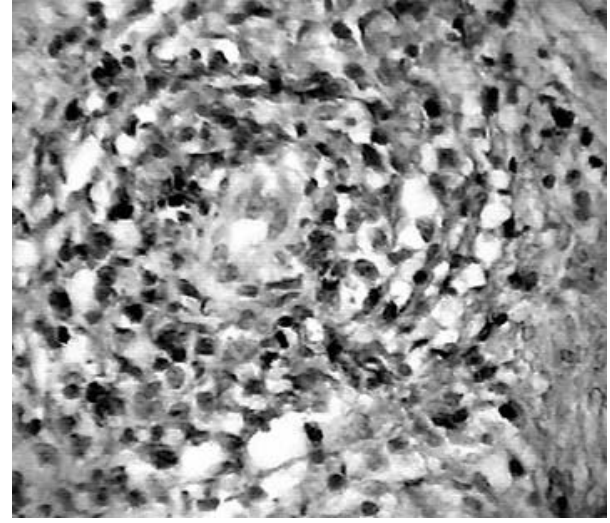

Figure 2 Polymorphic angiocentric proliferation depicting frequent $\mathrm{CD} 45 \mathrm{RO}+$ small lymphocytes among the larger lymphomatous cells. Case 1.

\section{CASE 2}

This 13 year old boy was being followed up for a left sided supraclavicular lymphadenopathy that enlarged progressively over six months. Surgical resection produced a $5 \times 4 \times 4 \mathrm{~cm}$ lymph node with increased consistency, showing pink to whitish patches of the sectioned surface. Histology of the lymph node revealed features similar to those of case 1. However, in this specimen, the lymphomatous infiltrates were somewhat more monomorphous and there were clearcut remnants of lymph node histology at several points at the periphery. Less involved areas of the lymph nodes contained numerous eosinophils. The areas of necrosis showed geographical contours partially delimited by fibroblast spindle cells (fig 4). Densely collagenised areas were also seen. The whole picture suggested a progression from angiocentric and angiodestructive lesions leading to infarcts, which were then organised and transformed into scarred areas. Immunohistochemistry showed the lymphomatous cells to be CD45RO+ (fig 5), CD30+ (fig 6), CD56+, and CD20-. In situ hybridisation for EBV encoded RNA was negative. The histological and immunohistochemical findings were similar to so called angiocentric T/NK cell lymphoma, nasal type.

The staging investigation revealed probable involvement of the mediastinal lymph nodes. Nose and paranasal sinuses were unremarkable.

\section{DISCUSSION}

AIL lesions involving lymph nodes are rare. Notably, a recent series from Japan include 14 cases grouped under the heading of AIL type II (four cases) and type III ( 10 cases), ${ }^{4}$ following an already reported classification. ${ }^{6}$ Not all were of the same immunophenotype, and the series encompassed B cell, T cell, and NK cell cases, sometimes associated with EBV. None presented in children.

AIL can occur in children but is seen in extranodal sites. To our knowledge, there are no reports of AIL or AL initially affecting lymph nodes in children.

Immunosuppressed patients, especially those undergoing treatment for leukaemia, can present EBV induced lymphoproliferative lesions, either nodal or extranodal, which usually respond well after the patient recovers an adequate immune status. ${ }^{7-11}$ However, we are not aware of descriptions of lesions with an angiocentric pattern under these circumstances. Lymphomatoid granulomatosis has been described in patients with Wiskott-Aldrich syndrome, a type of primary immunodeficiency, ${ }^{12}$ and in other conditions in which there is an underlying immune defect. It seems to be agreed that some cases originally defined as lymphomatoid granulomatosis are indeed examples of B cell lymphomas associated

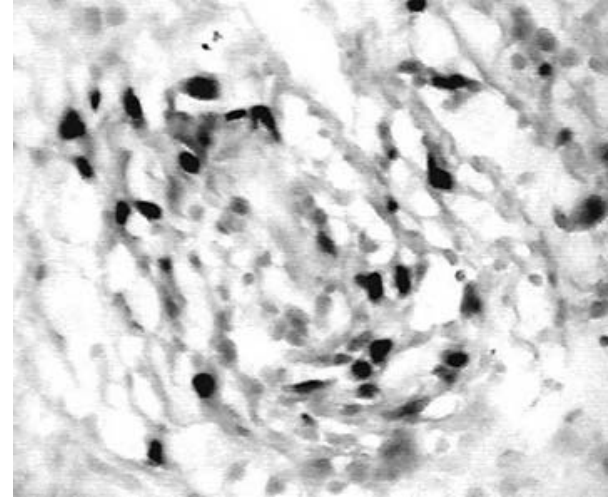

Figure 3 An angiocentric lesion showing strong nuclear reactivity after in situ hybridisation for Epstein-Barr virus encoded RNA in the large lymphomatous cells. Case 1.
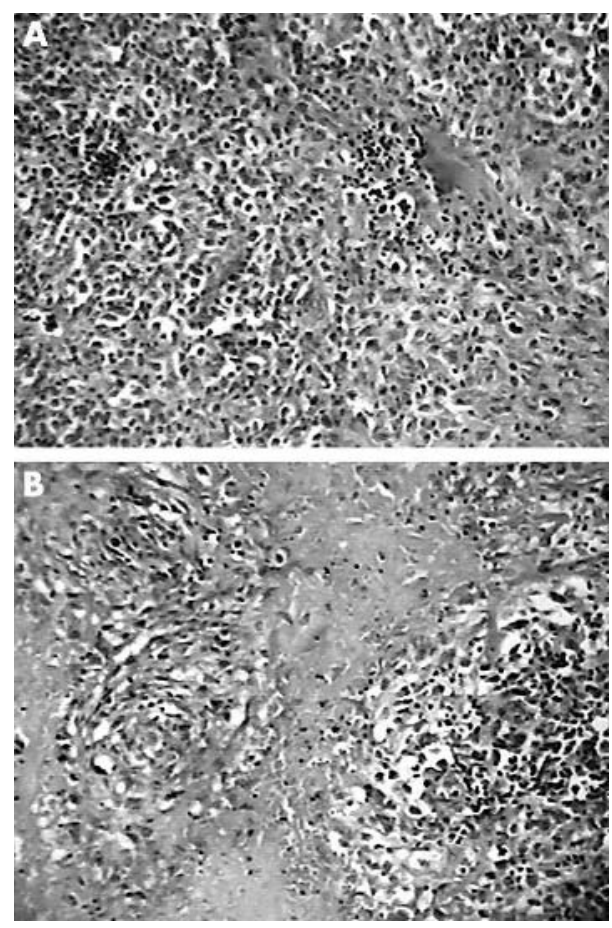

Figure 4 (A) An area of the lymph node involved predominantly by large cells showing a small spot of necrosis; (B) two angiocentric foci as related to the extensive areas of necrosis. Case 2.

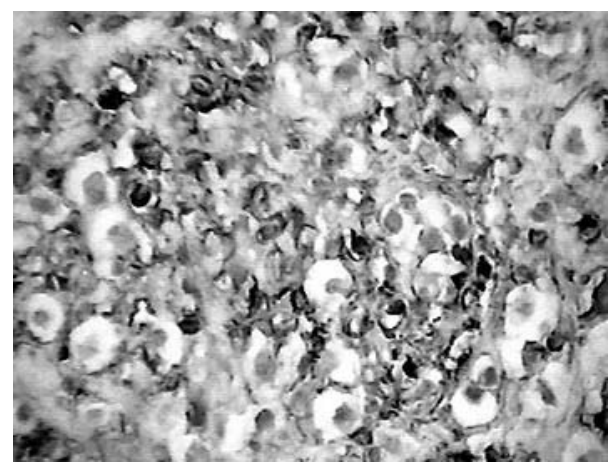

Figure 5 Densely cellular angiocentric area with large cells expressing CD45RO at the cytoplasmic contour. Case 2. 


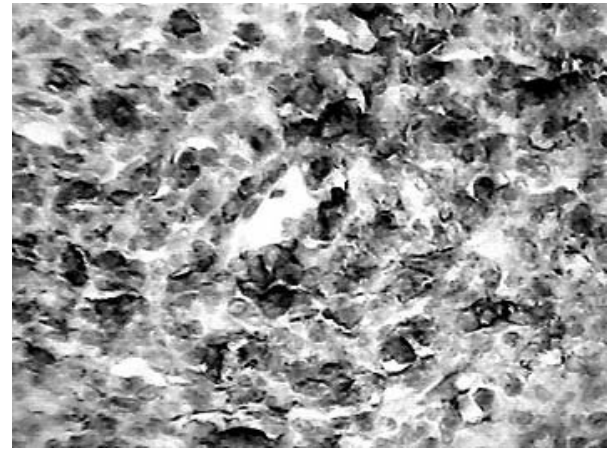

Figure 6 Densely cellular angiocentric area with large cells expressing CD30 at the cytoplasmic contour. Case 2.

\section{Take home messages}

- We report two examples of an angiocentric immunoproliferative lesion and angiocentric angiodestructive lymphoma presenting in lymph nodes in children

- These lesions are usually seen at extranodal sites, and rarely present in the spleen and lymph nodes

- These lesions are unusual in children but are easily recognised by their extremely unusual angiocentric pattern

with EBV, ${ }^{13}$ and that high grade AIL (indistinct from angiocentric lymphomas) can be shown to express EBV genomes by in situ hybridisation. ${ }^{14}$ Therefore, grade III lymphomatoid granulomatosis/AIL is regarded as a subtype of diffuse large B cell lymphoma. ${ }^{15}$ Notably, lymph nodes and spleen seem to be very rarely involved in lymphomatoid granulomatosis. ${ }^{15}$

That is why we entertained the diagnosis of lymphoma in case 1, a child undergoing treatment for ALL for 18 months, who presented with an EBV+ B cell AIL in a cervical lymph node. EBV associated B cell lymphoproliferation may occur in children undergoing treatment for ALL. Reported cases have been in extranodal sites, have represented fatal acute EBV infection with haemophagocytic syndrome, or the patients have recovered after discontinuation of immunosuppressive drugs..$^{7-11}$ Although speculative, we hypothesised that the uneventful recovery of our present patient may have resulted from the effect of the chemotherapy given for ALL acting on the EBV positive B cell angiocentric lymphoma.

The microscopic findings of case 2 correspond with those found in angiocentric T/NK cell lymphoma, nasal type, extranasal. ${ }^{16}$

Molecular studies are beyond our scope and were not performed in these two cases.

The angiocentric distribution of the lymphomatous cells in these lesions is so unusual that it readily suggests the diagnosis.
In summary, we report two examples of the unusual involvement of lymph nodes by AIL/AL, which only very rarely presents in children.

\section{Authors' affiliations}

R Drut, R M Drut, Department of Pathology, Hospital de Niños "Superiora Sor María Ludovica", 1900, La Plata, Argentina

The patients gave their permission for these cases to be published.

Correspondence to: Dr R Drut, Department of Pathology, Hospital de Niños "Superiora Sor María Ludovica", 1900, La Plata, Argentina; patologi@netverk.com.ar

Accepted for publication 30 September 2004

\section{REFERENCES}

1 Drut R. Angiocentric B-cell lymphoma of the lung in an immunocompromised boy. Pediatr Pathol 1988;8:395-400.

2 Tanaka Y, Sasaki Y, Kurozumi H, et al. Angiocentric immunoproliferative lesion associated with chronic active Epstein-Barr virus infection in an 11-yearold boy. Clonotopic proliferation of Epstein-Barr virus-bearing $\mathrm{CD}^{+} \mathrm{T}$ lymphocytes. Am J Surg Pathol 1994; 18:623-31.

3 Mizuno T, Takanashi Y, Onodera H, et al. A case of lymphomatoid granulomatosis/angiocentric immunoproliferative lesion with long clinical and diffuse brain involvement. J Neurol Sci 2003;213:67-76.

4 Takeshita M, Akamatsu M, Ohshima K, et al. Angiocentric immunoproliferative lesions of the lymph node. Am J Clin Pathol 1996;106:69-77.

5 Kueck BD, Hanson CA, Weissman DE, et al. Primary lymph node presentation of angiocentric lymphoma associated with features of hemophagocytic syndrome. Am J Hematol 1989;30:104-11.

6 Jaffe ES. Post-thymic lymphoid neoplasia. In: Jaffe ES, ed. Surgical pathology of the lymph node and related organs. Major problems in pathology, Vol. 16. Philadelphia: WB Saunders, 1985, 218-248, 329-356.

7 Look AT, Naegele RF, Callihan T, et al. Fatal Epstein-Barr virus infection in a child with acute lymphoblastic leukemia in remission. Cancer Res $1981: 41: 4280-3$

8 Joncas JH, Russo P, Brochu P, et al. Epstein-Barr virus polymorphic B-cell lymphoma associated with leukemia and with congenital immunodeficiencies. $J$ Clin Oncol 1990;8:378-84.

9 Mustafa MM, Winick NJ, Margraf LB. Epstein-Barr lymphoproliferative disorder in children with leukemia: case report and review of the literature. $J$ Pediatr Hematol Oncol 1997; 19:77-81.

10 Perkkiö M, Riikonen P, Seuri R, et al. Successful treatment of monoclonal aggressive Epstein-Barr virus-associated B-cell lymphoproliferation disorder in a child with acute lymphoblastic leukemia. Med Pediatr Oncol 1999;32:447-9.

11 Pondarre C, Kebaili K, Dijoud F, et al. Epstein-Barr virus-related lymphoproliferative disease complicating childhood acute lymphoblastic leukemia: no recurrence after unrelated donor bone marrow transplantation. Bone Marrow Transplant $2001 ; 27: 93-5$.

12 Sebire NJ, Haselden S, Malone M, et al. Isolated EBV lymphoproliferative disease in a child with Wiskott-Aldrich syndrome manifesting as cutaneous lymphomatoid granulomatosis and responsive to anti-CD20 immunotherapy. $J$ Clin Pathol 2003;56:555-7.

13 Myers JL, Kurtin PJ, Katzenstein A, et al. Lymphomatoid granulomatosis. Evidence of immunophenotypic diversity and relationship to Epstein-Barr virus infection. Am J Surg Pathol 1995;19:1300-12.

14 Medeiros L, Jaffe ES, Chen Y-Y, et al. Localization of Epstein-Barr viral genomes in angiocentric immunoproliferative lesions. Am J Surg Pathol 1992; 16:439-47.

15 Jaffe ES, Wilson WH. Lymphomatoid granulomatosis. In: Jaffe ES, Harris NL, Stein $\mathrm{H}$, et al. Pathology and genetics of tumours of haematopoietic and lymphoid tissues. Lyon: IARC Press, 2001:185-7.

16 Chan JKC, Jaffe ES, Ralfkiaer E. Extranodal NK/T-cell lymphoma, nasal type. In: Jaffe ES, Harris NL, Stein $\mathrm{H}$, et al. Pathology and genetics of tumours of haematopoietic and lymphoid tissues. Lyon: IARC Press, 2001:204-7. 